Gut and Liver, Vol. 10, No. 5, September 2016, pp. 781-785

\title{
Microsatellite Instability Status of Interval Colorectal Cancers in a Korean Population
}

Kil Woo Lee ${ }^{1}$, Soo-Kyung Park ${ }^{1,2}$, Hyo-Joon Yang ${ }^{1,2}$, Yoon Suk Jung ${ }^{1,2}$, Kyu Yong Choi ${ }^{1,2}$, Kyung Eun Kim ${ }^{2,3}$, Kyung Uk Jung ${ }^{2,4}$, Hyung Ook Kim ${ }^{2,4}$, Hungdai Kim ${ }^{2,4}$, Ho-Kyung Chun ${ }^{2,4}$, and Dong II Park ${ }^{1,2}$

${ }^{1}$ Division of Gastroentorology, Department of Internal Medicine, ${ }^{2}$ Gastrointestinal Cancer Center, Departments of ${ }^{3}$ Pathology, and ${ }^{4}$ Surgery, Kangbuk Samsung Hospital, Sungkyunkwan University School of Medicine, Seoul, Korea

Background/Aims: A subset of patients may develop colorectal cancer after a colonoscopy that is negative for malignancy. These missed or de novo lesions are referred to as interval cancers. The aim of this study was to determine whether interval colon cancers are more likely to result from the loss of function of mismatch repair genes than sporadic cancers and to demonstrate microsatellite instability (MSI). Methods: Interval cancer was defined as a cancer that was diagnosed within 5 years of a negative colonoscopy. Among the patients who underwent an operation for colorectal cancer from January 2013 to December 2014, archived cancer specimens were evaluated for MSI by sequencing microsatellite loci. Results: Of the 286 colon cancers diagnosed during the study period, 25 (8.7\%) represented interval cancer. MSI was found in eight of the 25 patients (32\%) that presented interval cancers compared with 22 of the 261 patients $(8.4 \%)$ that presented sporadic cancers $(p=0.002)$. In the multivariable logistic regression model, MSI was associated with interval cancer (OR, 3.91; 95\% confidence interval, 1.38 to 11.05). Conclusions: Interval cancers were approximately four times more likely to show high MSI than sporadic cancers. Our findings indicate that certain interval cancers may occur because of distinct biological features. (Gut Liver 2016;10:781-785)

Key Words: Colorectal neoplasms; Microsatellite instability; Colonoscopy

\section{INTRODUCTION}

Colonoscopy is considered the gold standard for the detection and prevention of colorectal cancer. Colorectal adenomatous polyps are accepted as the precursor lesion for colorectal cancer, so if colonoscopy can detect and remove all polyps, it can effectively reduce the incidence of colorectal cancer. However, colonoscopy is not a perfect examination, and some colorectal cancer is detected between colonoscopic surveillance examinations. Interval cancers have a negative impact on the ability to reduce the incidence of colorectal cancer. The development of interval cancers may represent the limitations of the colonoscopic technique, or differences in tumor biology resulting in rapid tumor growth.

Usually, interval cancer is defined as colorectal cancer that develops within 5 years of a complete colonoscopy. Previous reports have indicated that the incidence of interval cancer ranges from $3 \%$ to $8 \% .{ }^{1,2}$ There are several possible explanations for this discrepancy. First, some tumors may grow rapidly, representing actual new pathology that was not present at the time of the prior colonoscopy. Second, some tumors may have been missed at the time of colonoscopy for various reasons. Third, the neoplastic lesion may have been identified at the time of colonoscopy, but was incompletely resected. ${ }^{3}$

In a previous study, we reported the prevalence, clinicopathologic characteristics, and predictors of interval colorectal cancers in a Korean population. ${ }^{4}$

A previous Western study showed that interval colon cancers are three times more likely to have microsatellite instability (MSI) than sporadic cancers. ${ }^{5}$ Colon cancer is associated with loss of function of mismatch repair genes and accelerated tumor growth. ${ }^{6}$ In this study, we tested the hypothesis that interval cancers are more likely than sporadic cancers to exhibit MSI in a Korean population.

\footnotetext{
Correspondence to: Dong Il Park

Department of Internal Medicine, Kangbuk Samsung Hospital, Sungkyunkwan University School of Medicine, 29 Saemunan-ro, Jongno-gu, Seoul 03181, Korea

Tel: +82-2-2001-8555, Fax: +82-2-2001-8360, E-mail: diksmc.park@samsung.com

Received on August 6, 2015. Revised on November 3, 2015. Accepted on December 1, 2015. Published online April 28, 2016 pISSN 1976-2283 eISSN 2005-1212 http://dx.doi.org/10.5009/gnl15376

@ This is an Open Access article distributed under the terms of the Creative Commons Attribution Non-Commercial License (http://creativecommons.org/licenses/by-nc/4.0) which permits unrestricted non-commercial use, distribution, and reproduction in any medium, provided the original work is properly cited.
} 


\section{MATERIALS AND METHODS}

\section{Selection of study subjects}

We reviewed patients who underwent surgery for colorectal cancer and received a MSI test between January 2013 and December 2014 at Kangbuk Samsung Hospital. All patients underwent the operation at our hospital, but, in most cases, the index colonoscopy (colonoscopy performed before the diagnosis of colon cancer) was not performed at our hospital. We confirmed the previous colonoscopy history through medical records and patient interviews (face-to-face or over the phone). We excluded patients with colon cancer diagnosed within 1 year of an index colonoscopy, and patients with familial adenomatous polyposis, lynch syndrome (hereditary nonpolyposis colorectal cancer), inflammatory bowel disease, or recurred colorectal cancer. Patients were defined as having an interval cancer if they developed colon cancer within 5 years of a complete colonoscopy. Patients were defined as having a sporadic (noninterval) cancer if they were diagnosed with colon cancer on their first recorded colonoscopy or over 5 years after an index colonoscopy. Our institutional review board approved this study.

\section{Data collection and definitions}

Data extracted from patient medical records included comorbidities, lifestyle habits, and personal and family history of colorectal neoplasm (first-degree relatives). The American Joint Committee on Cancer (AJCC) Cancer Staging Manual was used to define and categorize study variables such as TNM cancer stage and histologic grade. The colon was divided into eight segments to describe the tumor location and these were collapsed into two categories: proximal colon (cecum, ascending, hepatic flexure, and transverse colon), and distal colon (splenic flexure, descending colon, and rectum). Mucinous carcinoma was defined as colon cancer with $>50 \%$ relevant histology.

\section{MSI analysis}

We used the presence of MSI to assess the loss of function of mismatch repair gene activity. MSI assays were performed on
DNA extracted from paraffin-embedded tissue blocks. Genomic DNA extraction and MSI testing of DNA samples was conducted at Samsung Medical Center in Seoul. In this study, MSI test was performed by multiplex polymerase chain reaction and analysis with a $3130 \times 1$ genetic analyzer. MSI testing of DNA samples was based on five dinucleotide markers (NR27, NR21, BAT26, BAT25, and NR24). Tumors that showed instability in $\geq 2 / 5$ of markers tested were classified as a high MSI and 1/5 of markers were classified as low MSI. Tumors that showed instability in 0/5 of markers were designated as microsatellite stable (MSS) cancers. Only high MSI cases were considered MSI positive.

\section{Statistical analysis}

Continuous variables are expressed as the median and range and categorical variables are absolute values or rates. Differences with respect to categorical covariates were evaluated using the chi-square test or Fisher exact test on appropriate crosstabulations, normally distributed continuous variables using the t-test, and nonnormally distributed continuous variables using the Wilcoxon rank sum test. Logistic regression analysis was used to adjust for confounders (sex, age, and tumor location) to the MSI and interval cancer association. Differences were considered significant when the two-sided p-value was $<0.05$. SPSS version 18.0 (SPSS Inc., Chicago, IL, USA) was used for data management and analysis.

\section{RESULTS}

From January 1, 2013 to December 31, 2014, there were 373 patients who underwent an operation for colorectal cancer at our hospital. Among these, 28 patients did not receive a MSI test, nine patients had recurred colorectal cancers, and two patients had inflammatory bowel disease. Of the remaining 334 patients, seven patients had an incomplete memory of prior colonoscopy, and 41 patients were not available for interview (Fig. 1).

In total, there were 286 patients who met the entry criteria for the study. Of these 286 cases, 261 patients had a colonoscopy
Fig. 1. Flow chart of the selection of study participants. MSI, microsatellite instability. 
at diagnosis (or after more than 5 years) and were classified as having sporadic cancer. A total of 25 individuals had a colonoscopy within 5 years before colorectal cancer diagnosis and were classified as having interval cancers. These interval cancers accounted for $8.7 \%$ of all colon cancers.

The interval time between the index colonoscopy and the second colonoscopy (at cancer diagnosis) was the average $35 \pm 12$ months, with a range of 15 to 57 months. Among the interval cancer group, 18 patients were male and seven were female. The mean age at diagnosis of interval cancer patients was $61 \pm 11$ years, with a range of 35 to 79 years.

A comparison of baseline characteristics between interval cancers and sporadic cancers is given in Table 1. There were no differences in age, sex, body mass index, risk factors, symptoms, previous abdominal surgery, or family history of colorectal cancer between patients with interval and sporadic cancer groups.

A comparison of tumor characteristics between interval and sporadic patients is shown in Table 2. The results of MSI analysis for the patients were as follows. MSI was demonstrated in eight patients (32\%) with interval cancer compared with 22 patients (8.4\%) with sporadic cancer $(\mathrm{p}=0.002)$. After adjusting for confounders, patients with interval cancer were approximately four times more likely to be MSI-positive than sporadic cancers

Table 1. Baseline Characteristics of Subjects with Interval and Sporadic Colon Cancer

\begin{tabular}{lccc}
\hline \multicolumn{1}{c}{ Characteristic } & $\begin{array}{c}\text { Interval } \\
\text { cancer } \\
(\mathrm{n}=25)\end{array}$ & $\begin{array}{c}\text { Sporadic } \\
\text { cancer } \\
(\mathrm{n}=261)\end{array}$ & $\mathrm{p}$-value \\
\hline Age, yr & $61.3 \pm 11.7$ & $62.8 \pm 12.9$ & 0.59 \\
Male sex & $18(72)$ & $153(58)$ & 0.19 \\
Body mass index, kg/m ${ }^{2}$ & $23.0 \pm 2.5$ & $23.0 \pm 2.4$ & 0.92 \\
Hypertension & $10(40)$ & $90(34.5)$ & 0.58 \\
Diabetes mellitus & $4(16)$ & $62(23)$ & 0.37 \\
Family history of colon cancer* & $3(12)$ & $19(7)$ & 0.42 \\
Presentation of symptoms $^{*}$ & $11(44)$ & $154(59)$ & 0.14 \\
Abdominal surgery $^{\text {Smoking }}{ }^{\dagger}$ & $6(24)$ & $48(18)$ & 0.59 \\
\hline
\end{tabular}

Data are presented as mean \pm SD or number (\%).

${ }^{*}$ Family history includes only first-degree relatives; ${ }^{\dagger}$ Smoking indicates a past or current smoker. (odds ratio [OR], 3.9; 95\% confidence interval [CI], 1.3 to 11.0) (Table 3). There was a significant difference in the location of the tumor between the two groups, with proximal colon cancers being much more common in the interval cancer group (13/25, $52 \%)$ than in the sporadic cancer group $(11 / 261,29 \%)$ in univariate analysis $(p=0.02)$. However, this association was not statistically significant in multivariable analysis (OR, 2.58; 95\% CI, 0.69 to $4.37 ; p=0.23$ ). There were no significant differences with regard to tumor size, TNM stage, or histologic grade between two groups.

A comparison between MSI-positive cancers and MSInegative (MSI-low or MSS) cancers was conducted. As shown in Table 4, MSI-positive cancers tended to occur in younger patients $(55.9 \pm 16.4$ years vs $63.4 \pm 12.1$ years, $\mathrm{p}=0.02)$, were larger $(5.7 \pm 2.0 \mathrm{~cm}$ vs $4.1 \pm 1.9 \mathrm{~cm}, \mathrm{p}<0.001)$, more frequently located in the proximal colon $(76 \%$ vs $26 \%, p<0.001)$, more likely to show a family association ( $20 \%$ vs $6 \%, p=0.018$ ), more likely to exhibit mucinous histology (20\% vs $2 \%, \mathrm{p}<0.001)$, and more likely

Table 2. Clinicopathological Characteristics of Interval and Sporadic Cancers

\begin{tabular}{|c|c|c|c|}
\hline Characteristic & $\begin{array}{c}\text { Interval cancer } \\
\quad(\mathrm{n}=25)\end{array}$ & $\begin{array}{c}\text { Sporadic cancer } \\
\quad(\mathrm{n}=261)\end{array}$ & p-value \\
\hline Tumor size, $\mathrm{cm}$ & $3.8 \pm 2.4$ & $4.3 \pm 2.0$ & 0.260 \\
\hline Location (proximal)* & $13(52)$ & 77 (29) & 0.020 \\
\hline MSI positivity $^{\dagger}$ & $8(32)$ & $22(8.4)$ & 0.002 \\
\hline TNM stage & & & 0.055 \\
\hline 1 & $9(36)$ & $55(21)$ & \\
\hline 2 & $8(32)$ & $72(27)$ & \\
\hline 3 & $6(24)$ & $101(38)$ & \\
\hline 4 & $2(8)$ & $33(12)$ & \\
\hline Histologic grade & & & 0.230 \\
\hline Well & $3(13)$ & $14(5)$ & \\
\hline Moderate & $19(86)$ & $232(91)$ & \\
\hline Poor & 0 & $7(3)$ & \\
\hline Mucinous $^{\ddagger}$ & $3(12)$ & $8(3)$ & 0.060 \\
\hline
\end{tabular}

Data are presented as mean \pm SD or number $(\%)$.

MSI, microsatellite instability.

*Proximal location represents cecum, ascending colon, and transverse colon; ${ }^{\dagger}$ MSI positive, tumors with $\geq 2 / 5$ markers showing MSI; ${ }^{\ddagger}>50 \%$ of tumors with mucinous histology.

Table 3. Risk Factors (or Predictive Factors) of Interval Cancer

\begin{tabular}{|c|c|c|c|c|c|c|}
\hline \multirow{2}{*}{ Variable } & \multicolumn{3}{|c|}{ Crude analysis } & \multicolumn{3}{|c|}{ Adjusted analysis } \\
\hline & OR & $95 \% \mathrm{CI}$ & $\mathrm{p}$-value & OR & $95 \% \mathrm{CI}$ & p-value \\
\hline $\mathrm{MSI}^{*}$ & 5.11 & $1.98-13.18$ & 0.002 & 3.91 & $1.38-11.05$ & 0.010 \\
\hline Location $^{\dagger}$ & 2.58 & $1.13-5.92$ & 0.020 & 1.74 & $0.69-4.37$ & 0.230 \\
\hline
\end{tabular}

Adjusted factors: sex, age, MSI, and location.

OR, odds ratio; CI, confidence interval; MSI, microsatellite instability.

*MSI positive, tumors with $\geq 2 / 5$ markers showing MSI; ${ }^{\dagger}$ Proximal location: cecum, ascending colon, and transverse colon. 
Table 4. Characteristics of Cancers by Microsatellite Instability Status

\begin{tabular}{|c|c|c|c|}
\hline Characteristic & $\begin{array}{l}\text { MSI-positive } \\
\text { cancer }(\mathrm{n}=30)\end{array}$ & $\begin{array}{l}\text { MSI-negative } \\
\text { cancer }(n=256)\end{array}$ & $\mathrm{p}$-value \\
\hline Age, yr & $55.9 \pm 16.4$ & $63.4 \pm 12.1$ & 0.020 \\
\hline Male sex & $21(70)$ & $150(58)$ & 0.220 \\
\hline Size, $\mathrm{cm}$ & $5.7 \pm 2.0$ & $4.1 \pm 1.9$ & $<0.001$ \\
\hline Location (proximal)* & $23(76)$ & $67(26)$ & $<0.001$ \\
\hline Family history $^{\dagger}$ & $6(20)$ & $16(6)$ & 0.018 \\
\hline Mucinous $^{\ddagger}$ & $6(20)$ & $5(2)$ & $<0.001$ \\
\hline Histology & & & 0.005 \\
\hline Well & $2(8)$ & $15(6)$ & \\
\hline Moderate & $17(70)$ & 234 (93) & \\
\hline Poor & $5(20)$ & $2(1)$ & \\
\hline TNM Stage & & & 0.710 \\
\hline 1 & $4(13)$ & $60(23)$ & \\
\hline 2 & $15(50)$ & $65(25)$ & \\
\hline 3 & $8(26)$ & $99(38)$ & \\
\hline 4 & $3(10)$ & $32(12)$ & \\
\hline
\end{tabular}

Data are presented as mean \pm SD or number $(\%)$.

MSI, microsatellite instability.

${ }^{*}$ Cecum, ascending colon, and transverse colon; ${ }^{\dagger}$ First-degree relatives; ${ }^{\ddagger}>50 \%$ of tumors with mucinous histology.

to exhibit poor differentiation ( $20 \%$ vs $2 \%, p=0.005$ ) than MSInegative cancers. There were no differences with respect to sex or TNM stage between the two groups.

\section{DISCUSSION}

To our knowledge, this is the first study to evaluate the prevalence of MSI in Korean patients with interval colorectal cancer. The prevalence of MSI was 32\% in interval cancers compared to $8.4 \%$ in sporadic cancers. We found that interval cancers were about four times more likely than sporadic cancers to be MSI positive. MSI was independently associated with interval cancers.

The interval cancer rate of $8.7 \%$ in this study was comparable to that reported in previous Western studies. However, this results show a relatively high proportion of interval cancer than previous our study (6.2\%). ${ }^{4}$ The higher proximal location rate of interval cancer (52\%) was similar to that of previous studies, but only in univariate analysis. ${ }^{2,5,7,8}$ There were no significant differences with regard to age, sex, tumor stage and mucinous histology between the two groups in other studies. ${ }^{2,9}$ These differences are thought to be due to insufficient number of samples.

There are several explanations for the development of interval cancer. Basically, it can either be a technical problem with colonoscopy or a biological problem. In terms of technical problems associated with colonoscopy, it was impossible to observe the whole colon mucosa because of poor bowel preparation. As bowel preparation improves, the polyp detection rate increases. ${ }^{7}$ Inadequate bowel preparation has been hypothesized to be a risk factor for missed interval cancers. Second, the colonoscopy exam duration may not be sufficient. It was reported that colonoscopy withdrawal time has been associated with polyp detection rate. ${ }^{10,11}$ The quality control guidelines of colonoscopy recommend a minimum of six minutes or more. ${ }^{12}$ Third, incomplete resection of the polyp could be a reason for interval cancer. The causes of incomplete resection are large polyp size, sessile type, and location in a difficult area for endoscopic resection. In particular, if the polyp is more than $20 \mathrm{~mm}$, the potential for incomplete resection increases. ${ }^{13,14}$

Finally, a rapidly growing polyp can be a cause of interval cancer. The progression from adenoma to carcinoma is generally thought to span 10 years according to the time interval of the adenoma-carcinoma sequence. ${ }^{15}$ However, several studies have reported that some patients experience rapid progression to cancer from a small adenoma. ${ }^{16,17}$ There are some rapid pathways for colon cancer development: the mismatch repair pathway and the serrated pathway. Mismatch repair defects associated with MSI tumors lead to a rapid accumulation of mutations necessary for tumorigenesis and result in accelerated tumor growth. Hereditary nonpolyposis colorectal cancer is known as a fast growing tumor in association with a DNA mismatch repair (MMR) gene. ${ }^{18}$ The majority of MSI cancers are sporadic cancers due to loss of function of MMR gene activity from hypermethylation of the hMLH1 mismatch repair gene. ${ }^{19}$ MSI, even in patients without Lynch syndrome is associated with proximal tumor location and improved survival compared with MSS cancers and more rapid lesion growth. ${ }^{20,21}$ Tumors that arise from sessile serrated polyps also may contribute to interval cancers because of their proximal colon predominance and difficulty of detection at colonoscopy. ${ }^{1,22}$ These flat-type lesions in particular have a tendency to invade the submucosal layer even when they are small. Sessile serrated polyps were often associated with mutations in the BRAF oncogene, which is not typically seen in traditional adenomas. ${ }^{23}$ This BRAF mutation has been tightly linked to a specific DNA methylation aberrancy of $\mathrm{CpG}$ islands broadly referred to as the $\mathrm{CpG}$ island methylator phenotype, ${ }^{24}$ and CIMP-high/BRAF-mutation are associated with sessile serrated adenoma as well as with MSI. ${ }^{25,26}$ Therefore, we should always be aware of these types of lesions.

This study had some strength. This is the first report on the high prevalence of MSI in interval colorectal cancers in Koreans, and the third result worldwide. ${ }^{5,27}$ We reported the prevalence of interval cancers and MSI positive cancers in a generalized group.

The present study also had several limitations. First, we only analyzed a small number of patients with interval cancer in tertiary single center. Selection bias was inevitable. Our results may not be representative of prevalence of interval cancer in Korea. A large sample study is essential to further discuss the features of interval cancer. Second, most of the index colonoscopies were not performed at our hospital, so most of the information about index colonoscopy was obtained from patient's 
memory, some interval cancers were misclassified as sporadic cancer, or vice versa. There may be recall bias. Third, we did not know all the results of index colonoscopy, for instance, withdrawal time of examination, degree of bowel preparation, presence of adenoma or other lesions, and department of endoscopist. Therefore, we lacked the ability to distinguish the cause of interval cancers.

In conclusion, this study suggests that tumor biology may play an important role in the pathogenesis of interval cancer. Mismatch repair pathway defects are present in a significant proportion of interval colon cancer cases. Further research is needed to clarify the role of this pathway in the etiology of interval cancers.

\section{CONFLICTS OF INTEREST}

No potential conflict of interest relevant to this article was reported.

\section{REFERENCES}

1. Arain MA, Sawhney M, Sheikh S, et al. CIMP status of interval colon cancers: another piece to the puzzle. Am J Gastroenterol 2010;105:1189-1195.

2. Samadder NJ, Curtin K, Tuohy TM, et al. Characteristics of missed or interval colorectal cancer and patient survival: a populationbased study. Gastroenterology 2014;146:950-960.

3. Rex DK. Maximizing detection of adenomas and cancers during colonoscopy. Am J Gastroenterol 2006;101:2866-2877.

4. Kim CJ, Jung YS, Park JH, et al. Prevalence, clinicopathologic characteristics, and predictors of interval colorectal cancers in Korean population. Intest Res 2013;11:178-183.

5. Sawhney MS, Farrar WD, Gudiseva S, et al. Microsatellite instability in interval colon cancers. Gastroenterology 2006;131:1700-1705.

6. Lindblom A. Different mechanisms in the tumorigenesis of proximal and distal colon cancers. Curr Opin Oncol 2001;13:63-69.

7. Gonçalves AR, Ferreira C, Marques A, Ribeiro LC, Velosa J. Assessment of quality in screening colonoscopy for colorectal cancer. Clin Exp Gastroenterol 2011;4:277-281.

8. Cooper GS, Xu F, Barnholtz Sloan JS, Schluchter MD, Koroukian SM. Prevalence and predictors of interval colorectal cancers in medicare beneficiaries. Cancer 2012;118:3044-3052.

9. Erichsen R, Baron JA, Stoffel EM, Laurberg S, Sandler RS, Sørensen HT. Characteristics and survival of interval and sporadic colorectal cancer patients: a nationwide population-based cohort study. Am J Gastroenterol 2013;108:1332-1340.

10. Barclay RL, Vicari JJ, Doughty AS, Johanson JF, Greenlaw RL. Colonoscopic withdrawal times and adenoma detection during screening colonoscopy. N Engl J Med 2006;355:2533-2541.

11. Rex DK. Colonoscopic withdrawal technique is associated with adenoma miss rates. Gastrointest Endosc 2000;51:33-36.

12. Rex DK, Bond JH, Winawer S, et al. Quality in the technical per- formance of colonoscopy and the continuous quality improvement process for colonoscopy: recommendations of the U.S. Multi-Society Task Force on Colorectal Cancer. Am J Gastroenterol 2002;97:1296-1308.

13. Serrano M, Mão de Ferro S, Fidalgo P, Lage P, Chaves P, Dias Pereira A. Endoscopic mucosal resection of superficial colorectal neoplasms: review of 140 procedures. Acta Med Port 2012;25:288296.

14. Vormbrock K, Mönkemüller K. Difficult colon polypectomy. World J Gastrointest Endosc 2012;4:269-280.

15. Winawer SJ, Fletcher RH, Miller L, et al. Colorectal cancer screening: clinical guidelines and rationale. Gastroenterology 1997;112: 594-642.

16. Rijcken FE, Hollema H, Kleibeuker JH. Proximal adenomas in hereditary non-polyposis colorectal cancer are prone to rapid malignant transformation. Gut 2002;50:382-386.

17. Oono Y, Fu K, Nakamura H, et al. Progression of a sessile serrated adenoma to an early invasive cancer within 8 months. Dig Dis Sci 2009;54:906-909.

18. Peltomäki P. The genetics of hereditary non-polyposis colorectal cancer and non-polypotic colon cancer. Adv Exp Med Biol 1999;470:95-98.

19. Kane MF, Loda M, Gaida GM, et al. Methylation of the hMLH1 promoter correlates with lack of expression of hMLH1 in sporadic colon tumors and mismatch repair-defective human tumor cell lines. Cancer Res 1997;57:808-811.

20. Chao A, Gilliland F, Willman C, et al. Patient and tumor characteristics of colon cancers with microsatellite instability: a populationbased study. Cancer Epidemiol Biomarkers Prev 2000;9:539-544.

21. Hemminki A, Mecklin JP, Järvinen H, Aaltonen LA, Joensuu H. Microsatellite instability is a favorable prognostic indicator in patients with colorectal cancer receiving chemotherapy. Gastroenterology 2000;119:921-928.

22. Cha JM. Colonoscopy quality is the answer for the emerging issue of interval cancer. Intest Res 2014;12:110-116.

23. Spring KJ, Zhao ZZ, Karamatic R, et al. High prevalence of sessile serrated adenomas with BRAF mutations: a prospective study of patients undergoing colonoscopy. Gastroenterology 2006;131: 1400-1407.

24. Weisenberger DJ, Siegmund KD, Campan M, et al. CpG island methylator phenotype underlies sporadic microsatellite instability and is tightly associated with BRAF mutation in colorectal cancer. Nat Genet 2006;38:787-793.

25. Kambara T, Simms LA, Whitehall VL, et al. BRAF mutation is associated with DNA methylation in serrated polyps and cancers of the colorectum. Gut 2004;53:1137-1144.

26. Jass JR. Classification of colorectal cancer based on correlation of clinical, morphological and molecular features. Histopathology 2007;50:113-130.

27. Nishihara R, Wu K, Lochhead P, et al. Long-term colorectal-cancer incidence and mortality after lower endoscopy. N Engl J Med 2013;369:1095-1105. 